\title{
INTERNET DATABASE OF SCOLIOSIS SCREENING
}

Norbert Szakály ${ }^{1}$, Péter Tamás ${ }^{1}$, Tamás Terebessy ${ }^{2}$, Dóra Végvári ${ }^{2}$, Péter Marschalkó ${ }^{3}$, László

\section{Basch $^{4}$}

${ }^{1}$ Budapest University of Technology and Economics Mechanical engineering Faculty

${ }^{2}$ Semmelweis University Orthopedic Department

${ }^{3}$ Heim Pál Children Hospital, Orthopedic Department

${ }^{4}$ Sensitiv Ltd.

szakab@mogi.bme.bu

\section{Abstract}

In Gerinco2 project there are a lot of examinations. To store data of examination a new database created with Internet technology. The aim of database is to screen to explore of scoliosis and follow treatment ill of children.

Keywords: scoliosis screening, Internet, MySql, artificial intelligence

\section{Method, the structure of database}

There are two main parts of database. One of them is the database with its defined structure of a server. The other is a client program for doctors and assistants. The data structure is realized in MySQL ${ }^{1}$ system which is free of charge and it is able to serve more users in one time. The structure of database is shown on the Figure 1.

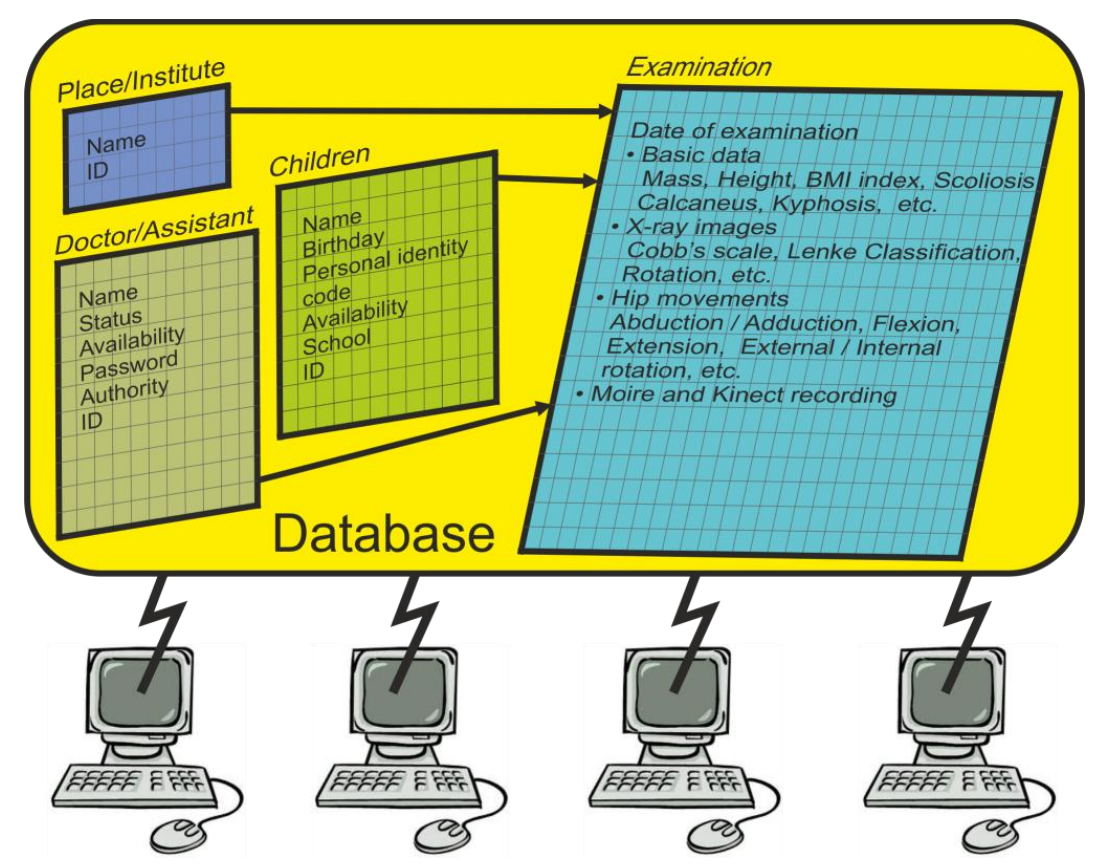

Figure 1. Structure of the database

Structure of the database ensures that the data traffic is as low as possible. Because of the used method the system is usable even on a week Internet connection. The pictures are stored on the 
server machine. Users download only the needed pictures. The downloaded pictures are stored in the client machine and they downloaded again only the case of changing.

There are four tables in database there. Data institutes and examiners authorized to use the system are stored two separate tables. The system uses different levels of authority and password so everybody can use only his own information.

The data of patients and the examinations are stored in the other two tables. In case of pupils the data of school and the class are stored. There are special identification numbers in the system so the personal identification data are not used. Results of all examinations are in the examination table.

\section{Result, the database management software}

System specification

Supported operating system:

Windows XP

Windows 7

Needed software:

MySQL ODBC Connector 5.1

Processor:

$1 \mathrm{GHz}$ Pentium processor

RAM:

$256 \mathrm{MB}$

Hard disk:

$50 \mathrm{MB}$ free space (suggested plus $500 \mathrm{MB}$ for the

downloaded pictures)

Display: $\quad 1024 \times 768$ high color, 32-bit

Internet connection is needed for usage of the system.

\subsection{Setup and upgrade}

GDB_setup.exe ( GDB_setup.exe) program installs the software in an interactive way. The user can define the position of the program in the machine and the Start menu. Default position of the program is C: \Program Files (x86) \GDB $\backslash$. (Figure 2.)

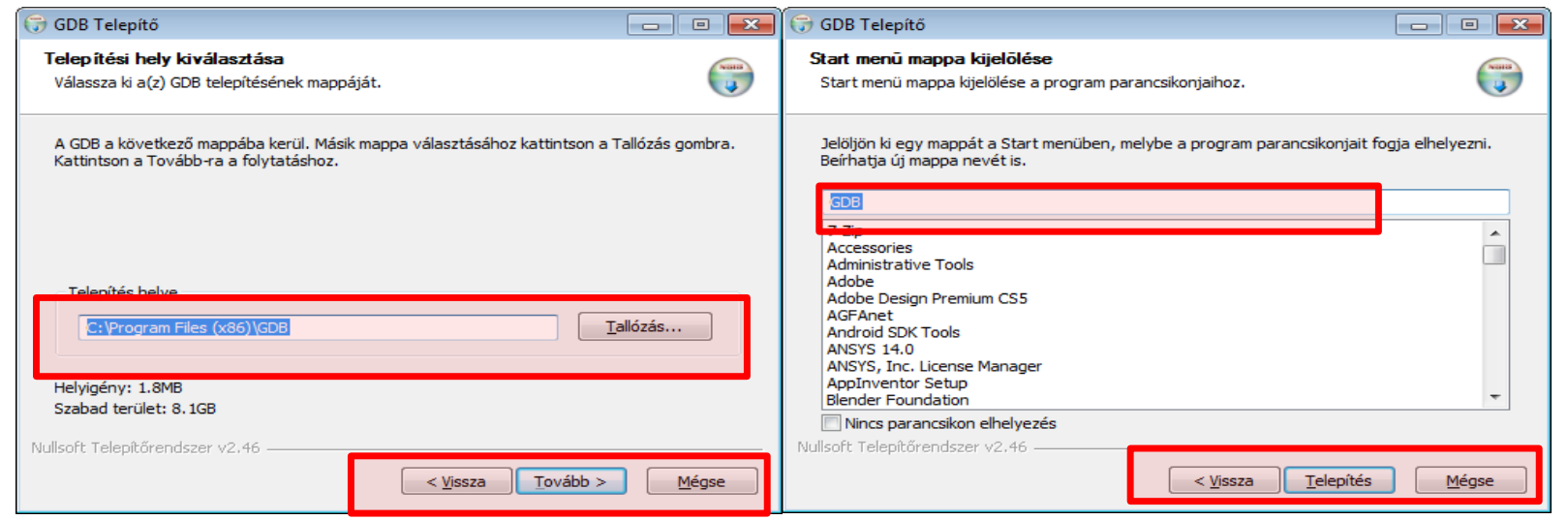

Figure 2. The setup dialog 
After setup there is an icon in the Desktop and the Start menu to start the program. The login panel of the program is shown in Figure 3.

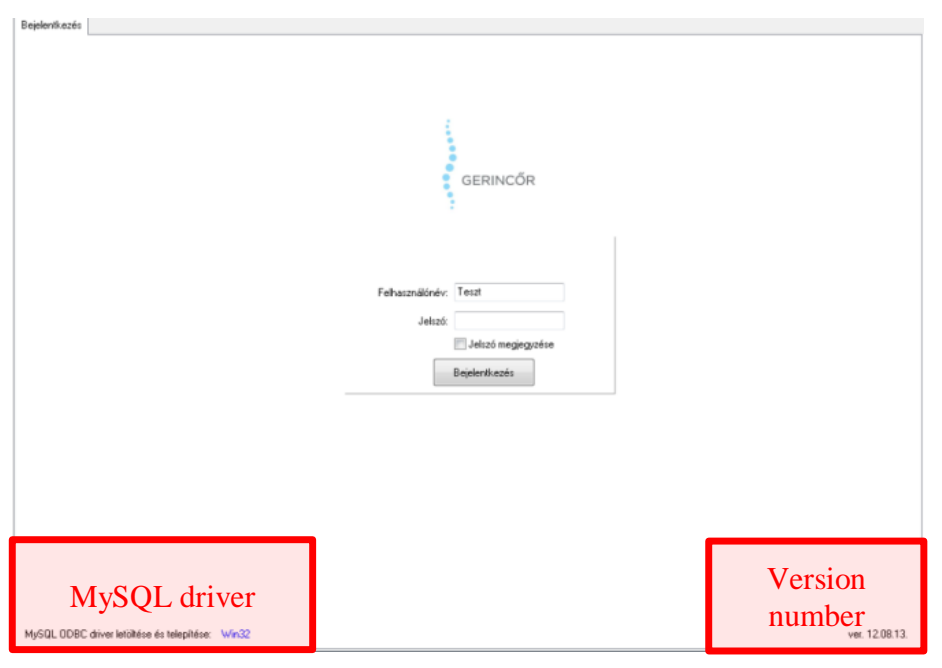

Figure 3. The login panel of GDB

The program is able to upgrade itself. After every ten usage the application searches for the newer version on the server. The needed version of MySQL ODBC driver also can be downloaded. After the log in we can use the software. The language of the communication is Hungarian.

\subsection{Data of examiners}

Data of examiners are username, name, qualification, status, address, phone number, e-mail, authorization, status (Figure 4). Examiners are able to change their own data (Figure 5.).

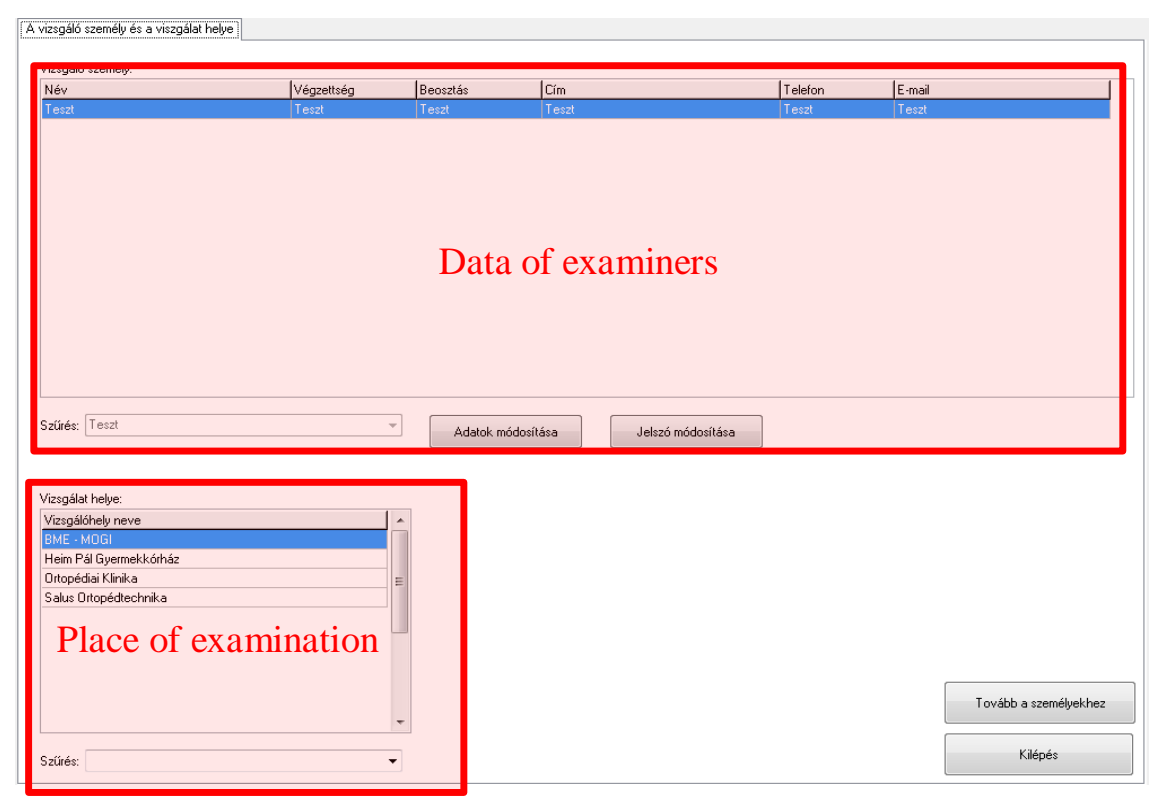

Figure 4. Data of examiners 


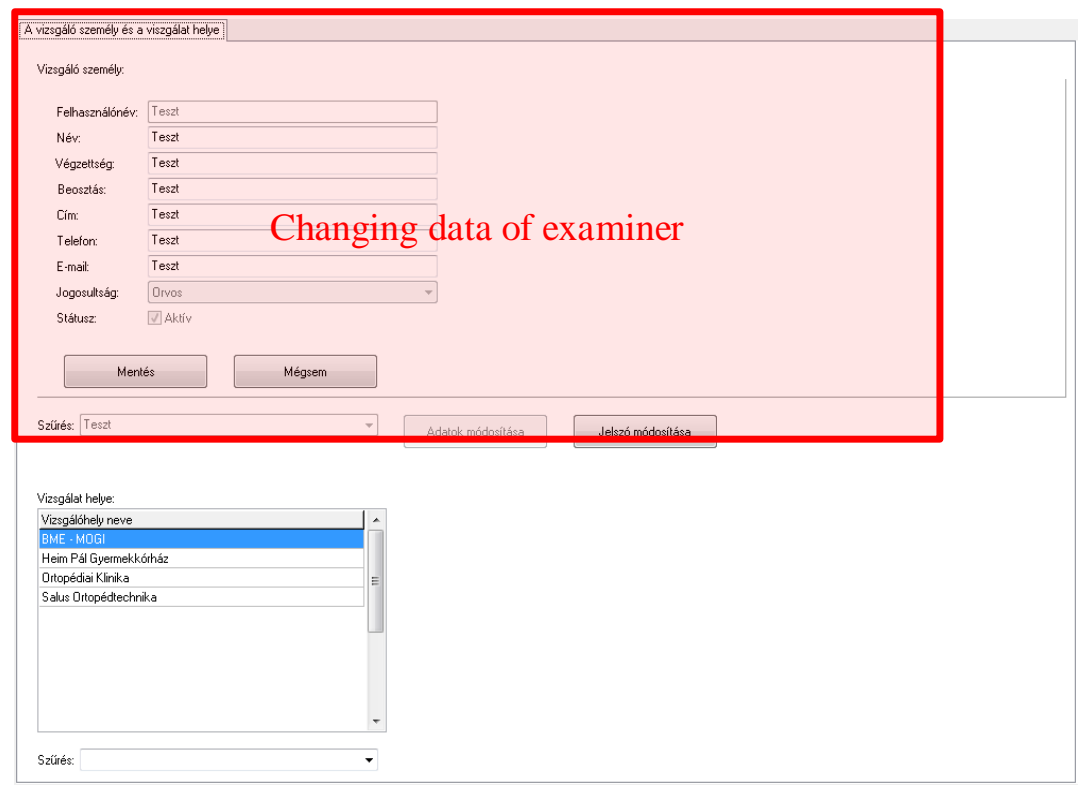

Figure 5. Modification of personal data of examiners

We can continue with the patient data.

\subsection{Data of patients}

Panel of patients data has three parts. Name of patients are in the left side. There is a filtering possibility to help the searching process. (Figure 6.)

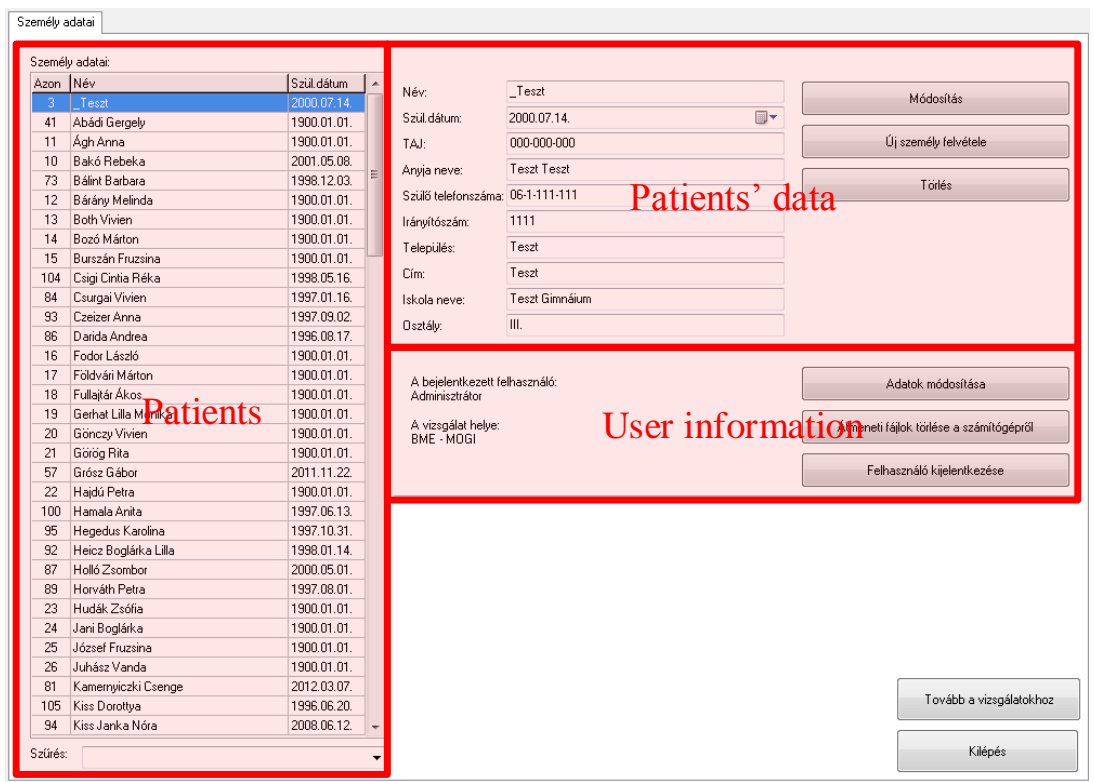

Figure 6. Patients' panel

Data of the selected patient (name, date of birth, name of mother, phone number, address, school, class) are shown in right side on the panel. There are possibilities to change or delete the patients. 
User name and place of the examination are the user information as they were defined at login phase.

\subsection{Data of examinations}

In the right side of dialog we can see the examinations. There is a possibility to choose an examination or create a new one. The selected examination data are shown in the dialog and we are able to modify or delete the data if we have enough rights. (Figure 7.)

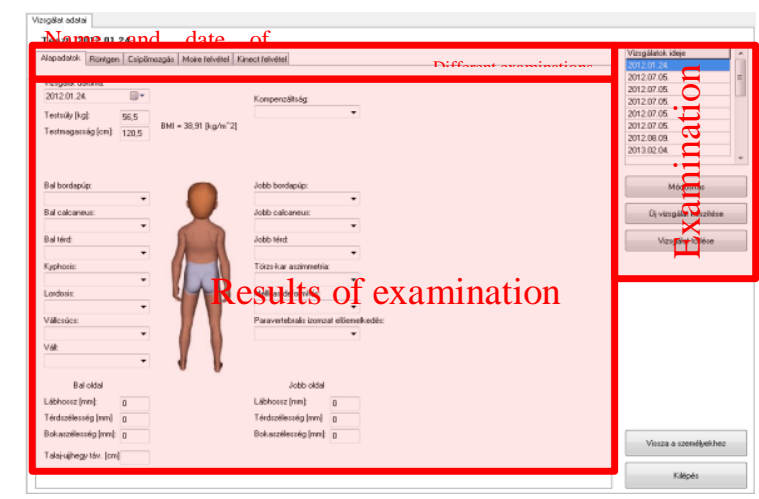

Figure 7. Results of examination

There are a lot of examination can be stored on database: the main data of the patient, X-Ray pictures, moving the hip, moiré and Kinect pictures.

\subsubsection{Main data of examinations}

The data can be stored are data of left rib hump, right rib hump, left calcaneus, right calcaneus, left knee, right knee, kyphosis, lordosis, shoulder, shoulder point, asymmetry of body-hand, deformity of chest paravertebralis muscle portrusion, left compensation, right compensation, data of legs

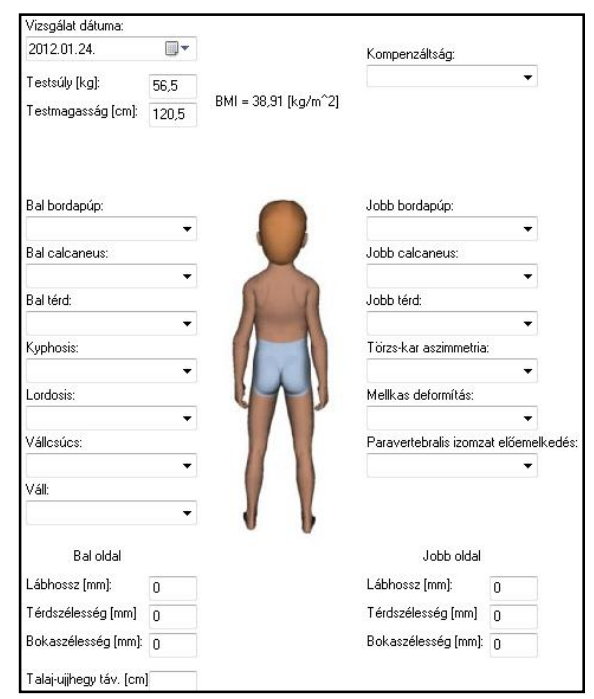

Figure 8. Main data 


\subsection{2 xRay pictures}

Panel of X-Ray there is a possibility to store and analyze the recorded pictures. (Figure 9.)

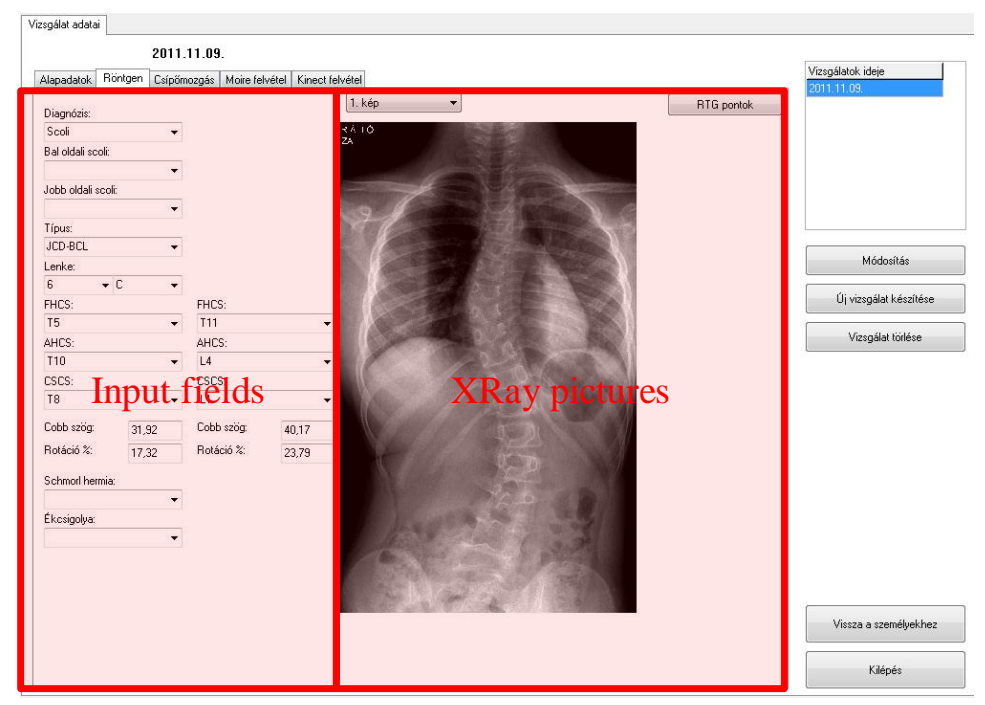

Figure 9. The X-Ray panel

In the left side there are some input field to store the diagnosis (Scoliosis, Scheuermann), the type of illness the Lenke classification ${ }^{2}$ factor and other data of vertebras (Cobb angle, rotation $^{3}$ ).

With help of a special function there is a possibility to analyze X-Ray pictures. On the Figure 10 there are some moveable line segments there with moveable endpoint of A, B, C, D, E, F and G. Of course the picture can be zoomed and rezoomed.
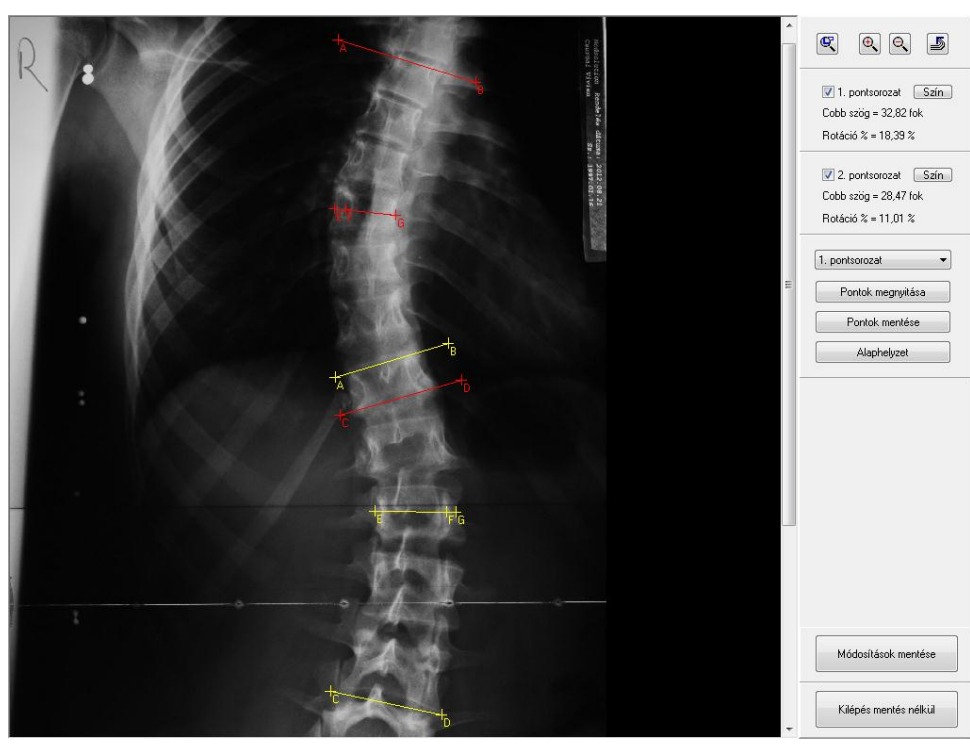

Figure 10. Analysis of X-Ray picture 
The angle between the $\mathrm{AB}$ and $\mathrm{CD}$ sections defines the Cobb angle, and $\mathrm{E}, \mathrm{F}$ and $\mathrm{G}$ sections defines the rotation, depend on the F (Figure 11).

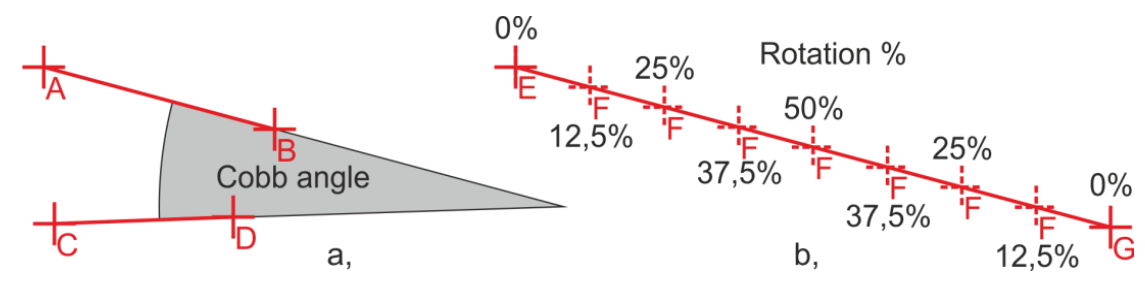

Figure 11. The Cobb angle (a,) and the rotation \% (b,)

\subsubsection{Hip movement}

On the Hip movement panel the user can define a lot of test data as we can see on the Figure 12.

\begin{tabular}{|c|c|c|c|c|c|c|}
\hline \multirow[b]{2}{*}{ Ext/Flexio: } & \multicolumn{3}{|c|}{ Left Site } & \multicolumn{3}{|c|}{ Right Site } \\
\hline & 10 & 0 & 110 & 10 & 0 & 125 \\
\hline Thomas test: & 0 & & & 0 & & \\
\hline Abd $\left(90^{\circ}\right)$ : & 35 & & & 35 & & \\
\hline Abd/Add $\left(0^{\circ}\right)$ : & 40 & 0 & 30 & 40 & 0 & 30 \\
\hline BRo/KRo $\left(90^{\circ}\right)$ : & 20 & 0 & 30 & 25 & 0 & 30 \\
\hline $\mathrm{BRo} / \mathrm{KRo}\left(0^{\circ}\right):$ & 25 & 0 & 10 & 40 & 0 & 15 \\
\hline Antetorsio: & 5 & & & 5 & & \\
\hline
\end{tabular}

Figure 12. Hip movement data

\subsubsection{Moiré (Kinect) analysis}

Either on the traditional moiré ${ }^{4}$ pictures or Kinect procedure ${ }^{5}$ there is a possibility to measure POTSI (POsterior TrunkSymmetry Index ${ }^{6}$ ) visible in Figure 13. or the Gerinco2 project evaluated Prediag method ${ }^{7}$ visible on Figure 14.

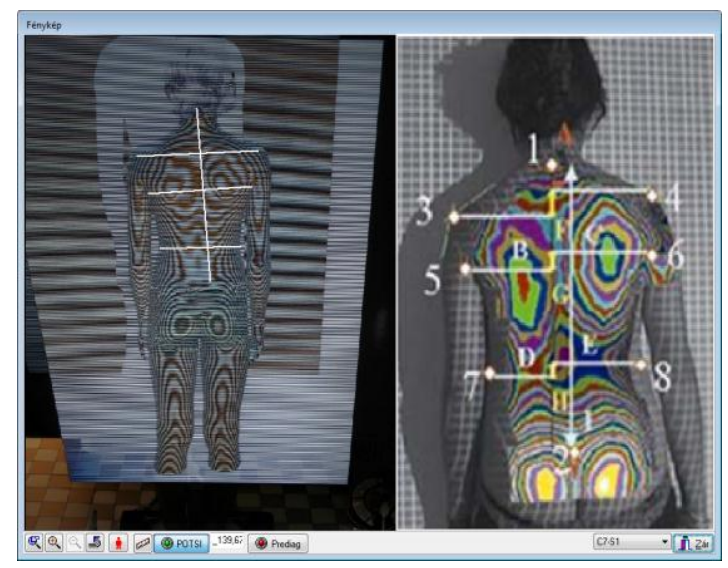

Figure 13. POTSI analysis 


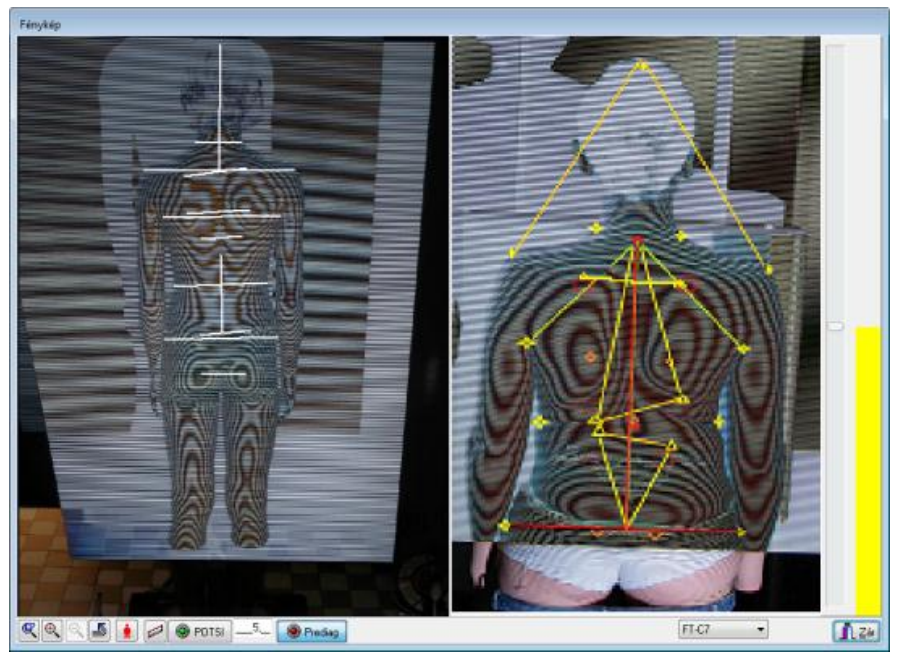

Figure 14. The Prediag analysis

\section{REFERENCES}

1. MySql : www.mysql.com 2013

2. King HA. Analysis and treatment of type II idiopathic scoliosis. Orthop Clin North Am. 1994;25:22537.

3. Cobb JR. Outline for the study of scoliosis. The American Academy of Orthopedic Surgeons Instructional Course Lectures. Vol. 5. Ann Arbor, MI: Edwards; 1948.

4. Jain AK, Figueiredo M, Zerubia J (editors) 2001. Energy Minimization Methods in Computer Vision and Pattern Recognition. Springer Verlag Berlin 2011.

5. Kinect - www.microsoft.com 2013.

6. Kinect- Minguez MF, Buendia M, Cibrián RM, Salvador R, Laguia M, Martin A, Gomar F. Quantifier variables of the back surface deformity obtained with a noninvasive structured light method: evaluation of their usefulness in idiopathic scoliosis diagnosis. Eur Spine J 2007;16:73-82.

7. Tamás P, Szakály N. Decision Help System Supported Data-mining Method. V. Magyar Biomechatronika Konferencia, Budapest 2013.

\section{National Office for Research and Technology (NKTH) of Hungarian Government for their support since this study has been carried out commonly as part of the project GERINCO2 TECH_08-A1/2-2008-0121.}

